\title{
Design of micro square endmills for hard milling applications
}

\author{
Peiyuan Li • J. A. J. Oosterling • A. M. Hoogstrate • \\ H. H. Langen $\cdot$ R. H. Munnig Schmidt
}

Received: 10 November 2010 / Accepted: 5 April 2011 /Published online: 20 April 2011

(C) The Author(s) 2011. This article is published with open access at Springerlink.com

\begin{abstract}
In experiments of machining hardened tool steels (such as AISI H11, H13, and D2, up to 56 HRC) by commercial Ø $0.5 \mathrm{~mm}$ square endmills, it is observed that the tested micro endmills showed severe wear at an early stage of the process due to chipping off around cutting edge corners, resulting in unsatisfactory tool life and product appearance (burr formation). Detailed examination of current tool geometry shows that it is mainly inherited from that of macro endmills, making the cutting edge corners the weakest part on the tool. As the micromilling process is characterized by small values of machining parameters, the cutting edge corners of the micro endmill are the most loaded part of the cutting edges. New design rules are studied for improving the stiffness and strength of micro endmills used in micro hard milling applications. Analytical modelling and finite element method analysis are used to aid the design of tool geometry. By using a larger neck angle, optimizing tool core geometry, and choosing a negative rake angle, tool stiffness and cutting edge strength are improved. The new endmill designs, both two-flute and four-flute, are tested in experiments on hardened tool steels and showed considerable lower tool wear and increased tool life. Furthermore, the geometrical accuracy and appearance of the workpiece (burr formation) has been improved drastically.
\end{abstract}

P. Li $(\bowtie) \cdot$ H. H. Langen $\cdot$ R. H. Munnig Schmidt

Department of Precision and Microsystems Engineering,

Delft University of Technology,

Mekelweg 2,

2628CD Delft, The Netherlands

e-mail: p.li@tudelft.nl

J. A. J. Oosterling • A. M. Hoogstrate

TNO Science and Industry,

P.O. Box 6235, 5600HE Eindhoven, The Netherlands
Keywords Micro hard milling · Endmill design . Modelling · Tool wear

\section{Introduction}

Micromilling is a promising technology for the manufacturing of micro moulds from hardened tool steels $[1,2]$ with three-dimensional features. It enables high production rates at lower cost where additional processing by EDM (electrical discharge machining) or ECM (electrochemical machining) could be reduced to a minimum, or even omitted. However, micro hard milling is not widely applied in industries yet due to its low process reliability. The main problem encountered is poor tool performance in terms of low stiffness and edge strength causing premature breakage, severe wear, and short tool life [3-9]. As a result, the quality of the machined workpiece cannot match the required specifications in applications [2, 9-15]. Some researchers stated that micro cutting tools have become the bottleneck of the micromilling technology $[16,17]$.

The performance of micro endmills is influenced by many aspects, not only the quality of micro endmills itself (e.g. tool material, coating, geometrical design, and tool manufacturing), but also the way it is used (e.g. machine tool, workpiece material, machining parameters, tool paths, and lubricant). In this paper, we study how the geometry of a micro endmill influences its performance, especially in hard milling applications.

Schmidt et al. conducted micromilling experiments by using commercial micro endmills to machine steels (SAE1045). They reported that the geometry of commercial micro tools was 'basically scaled down from conventional milling tools' [16], instead of being specially designed for micromilling. Uhlmann and Schauer [17] studied the 
geometry of commercial micro endmills by means of experimental and theoretical (finite element method (FEM) analysis) studies. Experiments were conducted by using different sizes of micro endmills $(\varnothing 0.4 \sim 1 \mathrm{~mm}$ ) to machine steels under different conditions (cutting speed, feed per tooth, and depth of cut). They concluded that the low reliability of commercial tools was due to the inappropriate design of tool geometry, and they tried to tackle this problem by introducing new tool design. In their new design, the tool geometry was optimized by shortening the tool cutting part and introducing a continuous changeover into the neck section. The new tools were tested on tool steel PM X190CrVMo 20 with 62 HRC. Surface roughness $(\mathrm{Rz})$ and tool breakage were used as tool life criteria. The lifetime of micro endmills was enhanced up to $30 \%$. However, wear at the cutting edge of the tools was not addressed in their paper. Fang et al. [18] compared conventional tool geometry with two novel geometries, namely semi-circle and triangle shapes for the cutting part of the micro endmill, especially for micro endmills smaller than $0.2 \mathrm{~mm}$ in diameter. The study was done first theoretically (FEM) and then verified in experiments. Different tool failure mechanisms were studied in their work. It was concluded that the traditional tool geometry was not suitable for micro endmills smaller than $\varnothing 0.1 \mathrm{~mm}$. The semi-circle-based design had higher rigidity and wear resistance over the other two. When the tool diameter is smaller than $50 \mu \mathrm{m}$, a simple geometry (e.g. no helix) is preferable due to manufacturing limitations. Adams et al. applied simple geometry of straight cutting edges on $\varnothing$ $25 \mu \mathrm{m}$ endmills, which were manufactured with focused ion beam machining. These endmills successfully 'machined millimeter long trenches in 6061-T4 aluminum, brass, 4340 steel and polymethyl methacrylate' [19]. However, endmills in such a scale are mainly used for research and not commercially available yet.

It was also reported in the literature that micro square endmills showed different dominant wear types in machining when comparing high strength materials (e.g. hardened tool steels) and low strength materials (e.g. copper and aluminium). When machining low strength materials, the observed dominant tool wear types were flank wear and crater wear, and the cutting tools worn out slowly $[4,7,8]$. In milling high strength materials, micro tools mainly suffered from chipping off at the cutting edge corners resulting in high wear rates $[3,4,10]$ or premature breakage. This indicates that the geometry of micro endmills should be designed and chosen depending on the type of applications.

This paper presents the study on tool performance improvement by designing tool geometry adaptively. In Section 2, the observed wear types when using commercial micro square endmills are introduced. The relationship

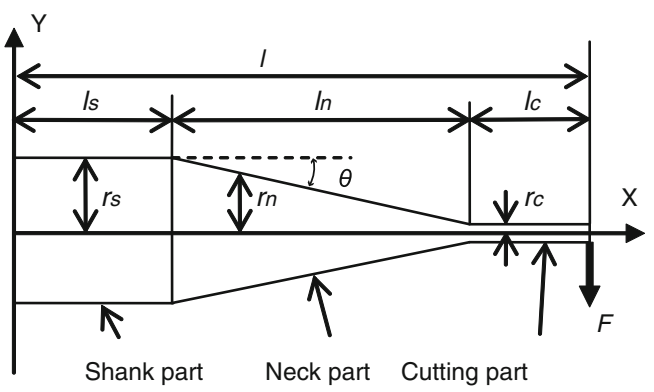

Fig. 1 Schematic overview of the micro endmill geometry. $l$ total length, $l_{\mathrm{s}}$ shank length, $l_{\mathrm{n}}$ neck length, $l_{\mathrm{c}}$ underneck length, $r_{\mathrm{s}}$ shank radius, $r_{\mathrm{n}}$ neck radius, $r_{\mathrm{c}}$ cutter radius, $\theta$ neck angle

between tool geometry and the observed dominant tool wear type is discussed. In Section 3, the influence of tool geometrical features on the tool performance is studied by FEM and analytical modelling. Tool geometry was redesigned based on the results from the theoretical analysis. Section 4 presents experimental verification of newly designed tools.

\section{Wear of the tested commercial micro endmills}

\subsection{Commercial micro square endmills}

Experiments were conducted with commercial $\varnothing 0.5 \mathrm{~mm}$ two-flute square endmills. All the endmills were made of sintered ultra-fine grain tungsten carbide with TiAlN coating. A rough sketch of the geometry of the endmill is illustrated in Fig. 1 and the key specifications are shown in Table 1. The commercial tool has a standard corner shape (no corner radius or chamfer), as shown in Fig. 2a, b; therefore, it can be used to machine features with straight corners. Examination of tool geometry showed that its design was derived from that of macro scale endmills. This means it uses the same values for some key geometrical

Table 1 Summary of the specifications of micro endmills

\begin{tabular}{llcc}
\hline & $\begin{array}{l}\text { Commercial } \\
\text { tool }\end{array}$ & $\begin{array}{l}\text { New design } \\
\text { 2-flute }\end{array}$ & $\begin{array}{l}\text { New design } \\
\text { 4-flute }\end{array}$ \\
\hline Cutting diameter $(\mathrm{mm})$ & 0.5 & 0.5 & 0.5 \\
Underneck length $(\mathrm{mm})$ & 0.8 or 3 & 0.5 & 0.5 \\
No. of flutes & 2 & 2 & 4 \\
Core radius $(\mathrm{mm})$ & 0.175 & 0.19 & 0.19 \\
Rake angle $\left(^{\circ}\right)$ & +8 & -8 & -8 \\
Radial relief angle $\left({ }^{\circ}\right)$ & 10 & 10 & 10 \\
Radial relief land $(\mathrm{mm})$ & 0.075 & 0.06 & 0.06 \\
Helix angle $\left({ }^{\circ}\right)$ & 30 & 20 & 20 \\
Neck angle $\left(^{\circ}\right)$ & 12 & 18 & 18 \\
Shank diameter $(\mathrm{mm})$ & 6 & 6 & 6 \\
\hline
\end{tabular}


Fig. 2 SEM photos of the cutting part of a new commercial Ø 0.5 -mm square endmill. a Top view, b side view
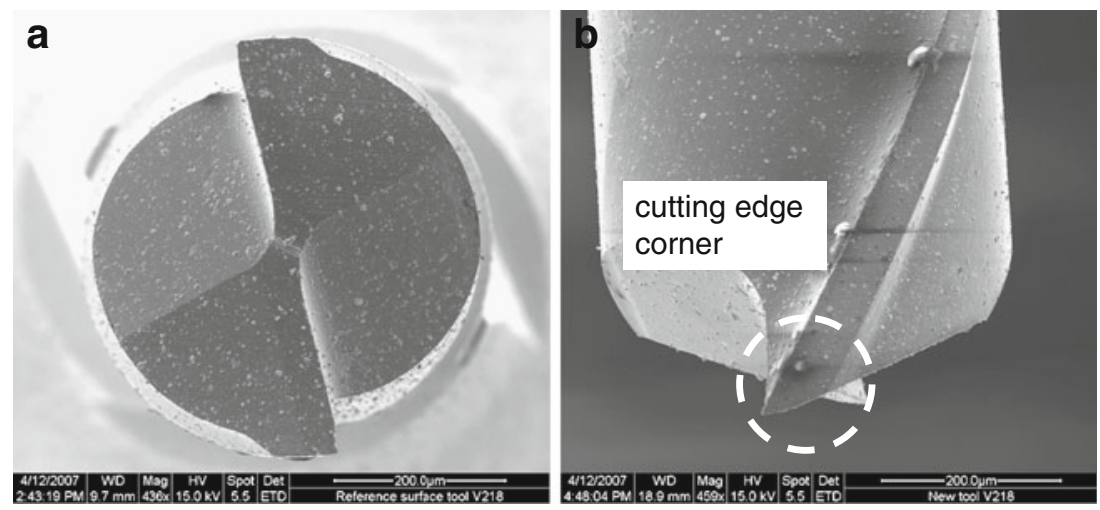

features as macro scale endmills, such as the rake angle, the relief angle, and the ratio between flute depth and cutting diameter. According to the specifications, this type of endmills is designed for high speed machining of steel up to $60 \mathrm{HRC}$. The recommended cutting parameters given by the tool supplier are: depth of cut $\left(a_{\mathrm{p}}\right) 0.02 \sim 0.37 \mathrm{~mm}$, width of cut $\left(a_{\mathrm{e}}\right) \quad 0.02 \sim 0.5 \mathrm{~mm}$, and feed per tooth $\left(f_{\mathrm{z}}\right)$ 0.005 0.009 mm, depending on the operation (e.g. side milling or slot milling).

\subsection{Difference in the cutting geometry between micro and macro scale milling}

There is a difference in cutting geometry between micro and macro scale milling. In macro scale milling, the cutting is done by side cutting edges and a small part of endface cutting edges. Because the applied $a_{\mathrm{p}}$ and $f_{\mathrm{z}}$ are relatively big (e.g. tens to approximately hundreds of micrometers), a small change at the cutting edge corners will not influence the tool geometry largely. However, in micromilling, small values for $a_{\mathrm{p}}$ and $f_{\mathrm{z}}$ (e.g. several to tens of micrometers) are normally applied to avoid severe tool bending and tool premature breakage, resulting in the fact that only cutting edge corners (where side- and endface cutting edges come together, as shown in Fig. 2) of micro square endmills are involved in cutting. It was observed in experiments that this difference in cutting geometry has led to different dominant wear types in micromilling.

\subsection{Observed tool wear}

Experiments were conducted to machine hardened tool steel (AISI H11, H13, and D2, up to 56 HRC) under different combinations of cutting conditions. The machine tools included Fehlmann PicoMax 60HSC and KERN EVO. It was found in experiments that the interface between the tool holder and spindle has an influence on the static runout at the end of the tool shaft. Before each experiment, the static runout was checked by using a high precision dial gauge. If the runout was bigger than $1 \mu \mathrm{m}$, the tool holder was taken out, cleaned, and re-inserted again. By repeating this process, the static runout could be adjusted to be smaller than $1 \mu \mathrm{m}$. Experiments were designed to minimize possible influence from factors other than tool geometry on tool life. Therefore, simple slot milling operation was adopted. Machining parameters were chosen according to the recommendations from the tool supplier. Chatter was monitored by checking the frequency component of the machining forces. No chatter occurred within the tested process window. Minimum quantity lubrication was used in all experiments. Tool
Fig. 3 SEM photos of the cutting part of a worn $\varnothing 0.5-\mathrm{mm}$ square endmill. a Top view and b side view. Compared with a new tool (such as shown in Fig. 2), chipping caused loss of a relatively large amount of tool material around cutting edge corners. Afterwards, abrasive wear happened on the newly formed blunt 'cutting edges'
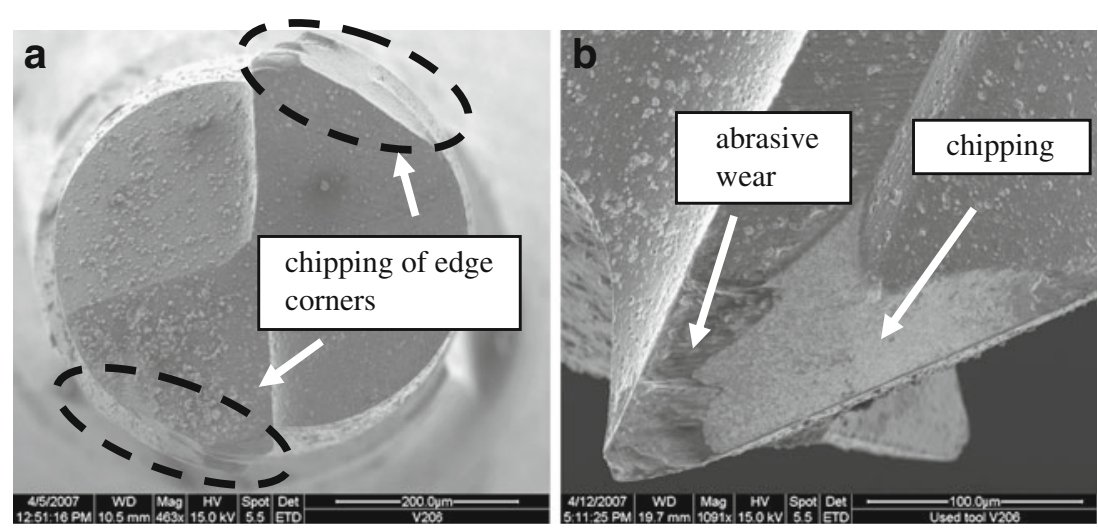


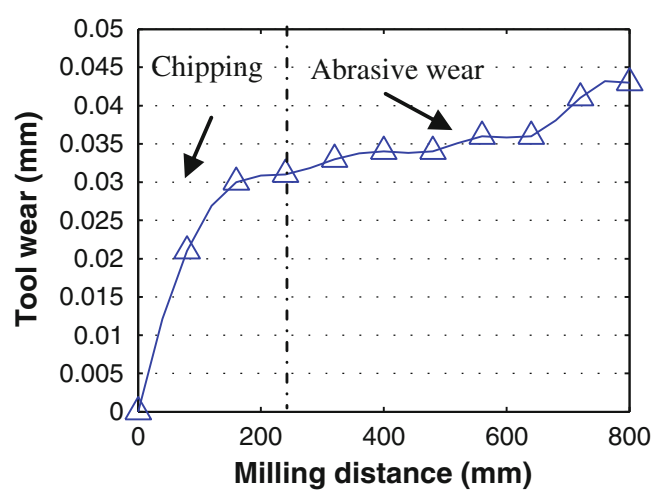

Fig. 4 Progress of tool wear as a result of chipping and abrasive wear. Tool wear was evaluated as reduction of the cutting diameter at the endface of the tool (explained in Section 2.4). Experimental conditions: cutting speed $v_{\mathrm{c}} 56.6 \mathrm{~m} / \mathrm{min}, a_{\mathrm{p}} 0.08 \mathrm{~mm}, a_{\mathrm{e}} 0.5 \mathrm{~mm}, f_{\mathrm{z}}$ $0.006 \mathrm{~mm}$, workpiece AISI H11 with $56 \mathrm{HRC}$

condition was observed regularly by means of FEI Quanta 600 scanning electron microscope and Keyence VHX-100 microscope at a certain cutting distance.

In general, it was observed that the tested commercial micro endmills suffered from severe tool wear at the cutting edge corners, as shown in Fig. 3. Compared with a new tool (shown in Fig. 2), a worn tool lost two cutting edge corners (shown in Fig. 3a). In Fig. 3b, two wear types are shownabrasive wear and chipping. They can be differentiated by studying the surface: the surface appears smooth after fracture, while the surface looks relatively rough due to abrasive wear.

In general, the observed main tool wear types included chipping, abrasive wear, and build up edge. Premature breakage of the whole cutting part did not happen in experiments. Tools normally wore out significantly before they broke due to fatigue. A typical tool wear progress curve is presented in Fig. 4. A sudden change is seen in the cutting diameter at the beginning of the machining (about $200 \mathrm{~mm}$ slot milling), which was due to chipping. Afterwards, the reduction of tool diameter became stable and gradual, which was attributed to abrasive wear. This figure shows that chipping is the dominant wear type and it should be avoided or minimized in order to improve tool life.

\subsection{Tool wear evaluation}

In order to evaluate tool wear quantitatively, a wear criterion has to be defined. The criterion needs to reflect the most prominent effect of tool wear on micro endmills, and it needs to be easy to implement.

In macro scale milling, flank wear is commonly used to evaluate wear of endmills. However, it is seen in Fig. 4 that flank wear only contributes partly to the change of geometry of micro endmills. Besides, due to the small geometry of micro endmill, it is difficult to measure flank wear on a worn tool. Therefore, flank wear was not chosen in this research as a tool wear evaluation criterion.

As stated in [20], micro components have very high requirements on form accuracy (relative accuracy in the order of $10^{-1}$ to $10^{-2}$ ). The form of the workpiece is actually a projection of the shape of the cutting tool. The effect of tool wear observed in this research was the reduction of tool cutting diameter at the endface. Therefore, reduction of the cutting diameter of the micro endmill was used as an indication of tool wear in this study, as demonstrated in Fig. 5. To use this criterion, the effect of runout on tool wear evaluation can also be minimized.

\subsection{Analysis of commercial tool geometry}

In order to find out the relation between tool geometry and tool performance, the finite element method was used to study the distribution of global stress distribution along the tool under micromilling forces. The stress distribution in the cross section of the tool (similar to orthogonal cutting) has been well studied in [21]; therefore, it is not discussed here.

Firstly, a computer-aided design (CAD) model of the micro square endmill was drawn in SolidWorks 2008 by using the same specifications as the tested commercial tools as listed in Table 1. Since the interest is the wear of the cutting edges, only the cutting part of the tool was drawn, as shown in Fig. 6a. Secondly, adaptive meshing was used to refine the mesh in the critical regions, such as the cutting edge corners. Thirdly, evenly distributed static forces were
Fig. 5 Tool edge corners were totally gone after the tool wore out, which resulted in a reduction of tool cutting diameter. This will be reflected on the machined features. a Side view of a new tool, $\mathbf{b}$ side view of a worn tool
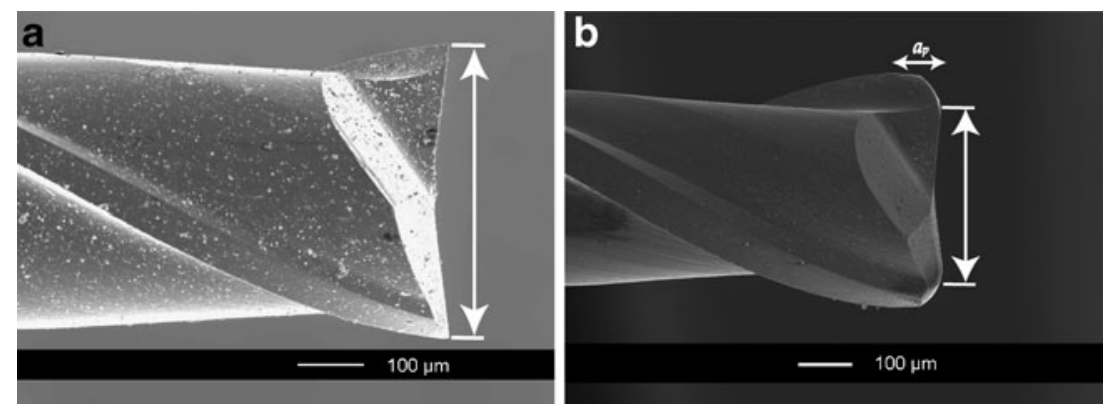
Fig. 6 FEM analysis of tool geometry: a illustration of meshing and force application and $\mathbf{b}$ maximum normal stress locates at the cutting edge corner

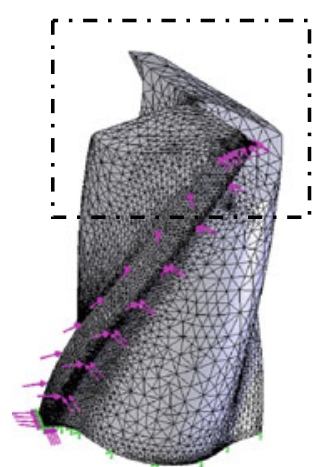

a

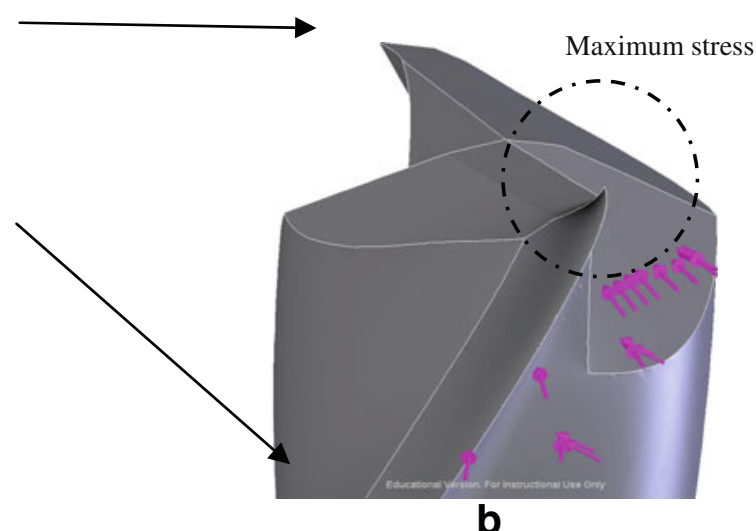

applied in the normal direction of the rake face and flank face of one of the side cutting edge (because only one cutting edge is immersed in the workpiece at any time during machining). No force was applied on the cutting edges on the endface because they were actually not involved in cutting due to the small value of $f_{\mathrm{z}}$. The

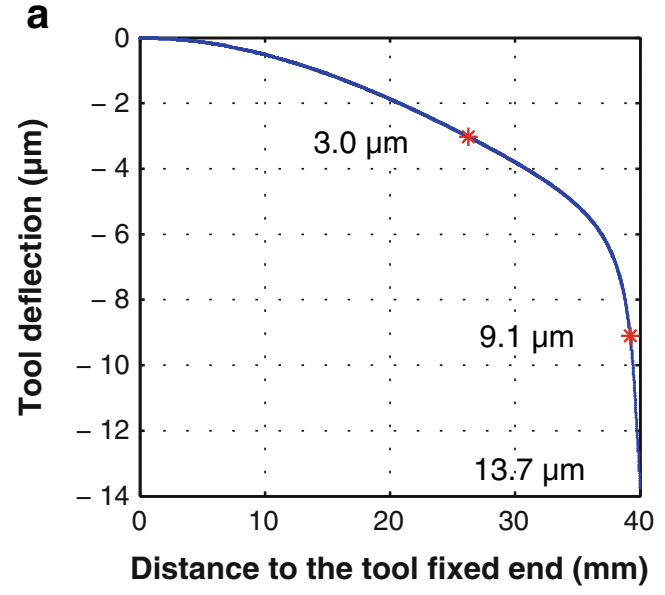

b

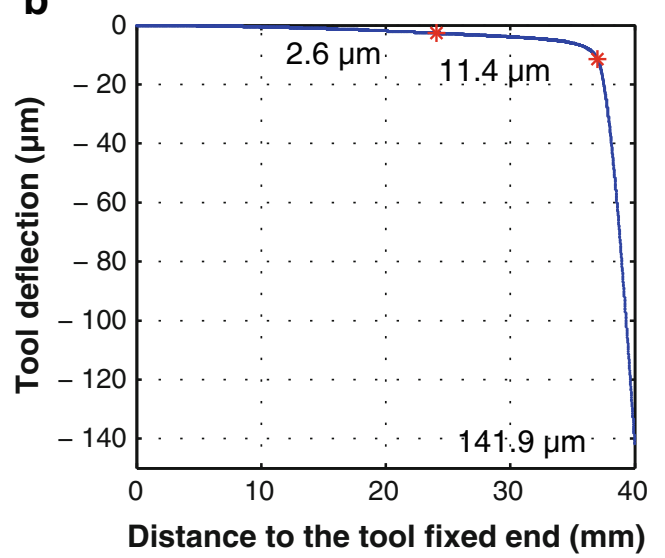

Fig. 7 Calculated deflection of a $\varnothing 0.5-\mathrm{mm}$ endmill, and the transition between different parts of the tool is marked by a star. a Tool with an underneck length of $0.8 \mathrm{~mm}$ and $\mathbf{b}$ tool with an underneck length of $3 \mathrm{~mm}$ validity of this assumption is confirmed by the measured neglectable force in experiments in the axial direction for a new tool. Finally, a static analysis was conducted to study the global stress distribution along the cutting edge. The simulation was done in COSMOSWorks 2008. The Young's modulus of tungsten carbide is $560 \mathrm{GPa}$, the transverse rupture strength is $4,200 \mathrm{MPa}$, and Poisson's ratio is 0.24 .
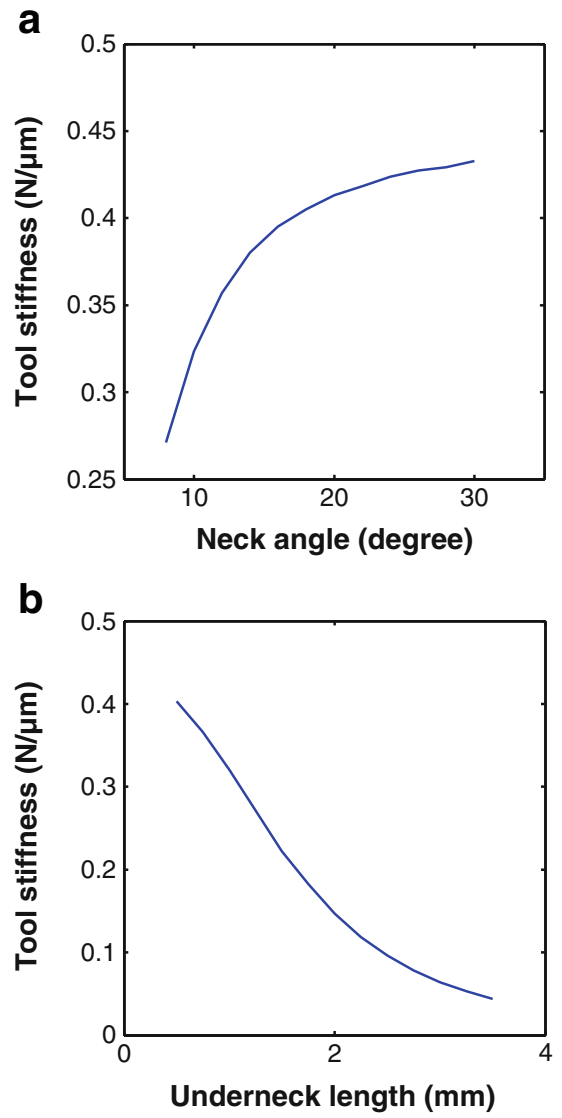

Fig. 8 Influence of a tool neck angle and $\mathbf{b}$ underneck length on the tool stiffness. Conditions: tool total length is $60 \mathrm{~mm}$, shank diameter $6 \mathrm{~mm}$, cutting diameter $0.5 \mathrm{~mm}$ 
Fig. 9 Influence of tool geometrical features on the maximum stress level on the tool cutting edge. a Effect of radial rake angle, $\mathbf{b}$ radial relief angle, $\mathbf{c}$ helix angle, and $\mathbf{d}$ core radius

Fig. 10 CAD drawings of the newly designed tools. a Cutting part of the two-flute tool, $\mathbf{b}$ cutting part of the four-flute tool, $\mathbf{c}$ cross section of the cutting part of the two-flute tool, and $\mathbf{d}$ illustration of negative rake angle a

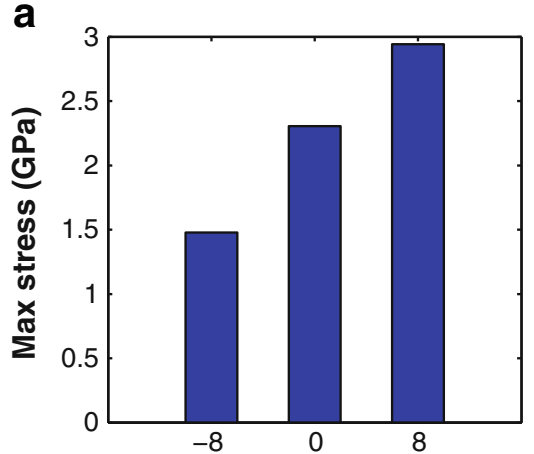

Rake angle (degree)

C
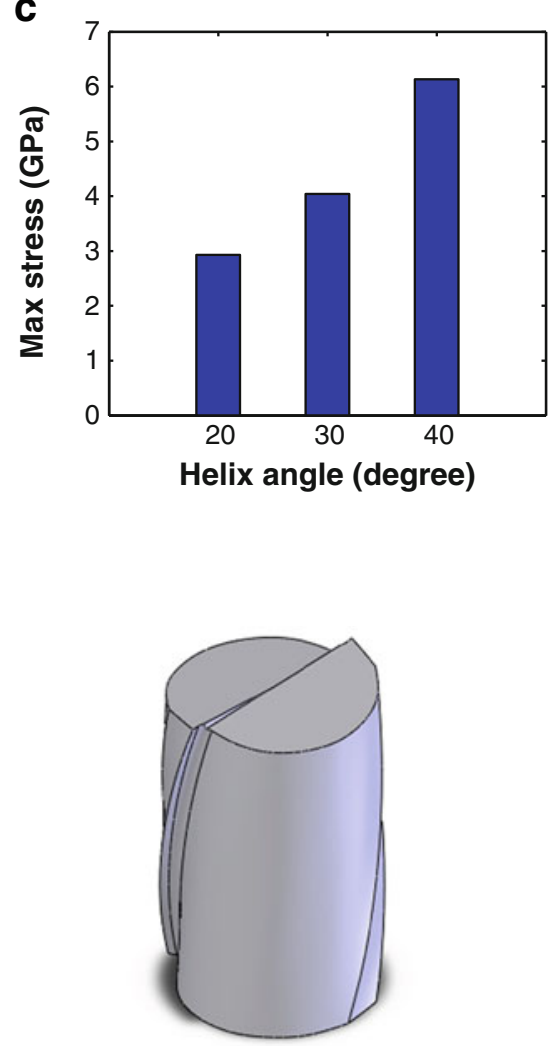

a

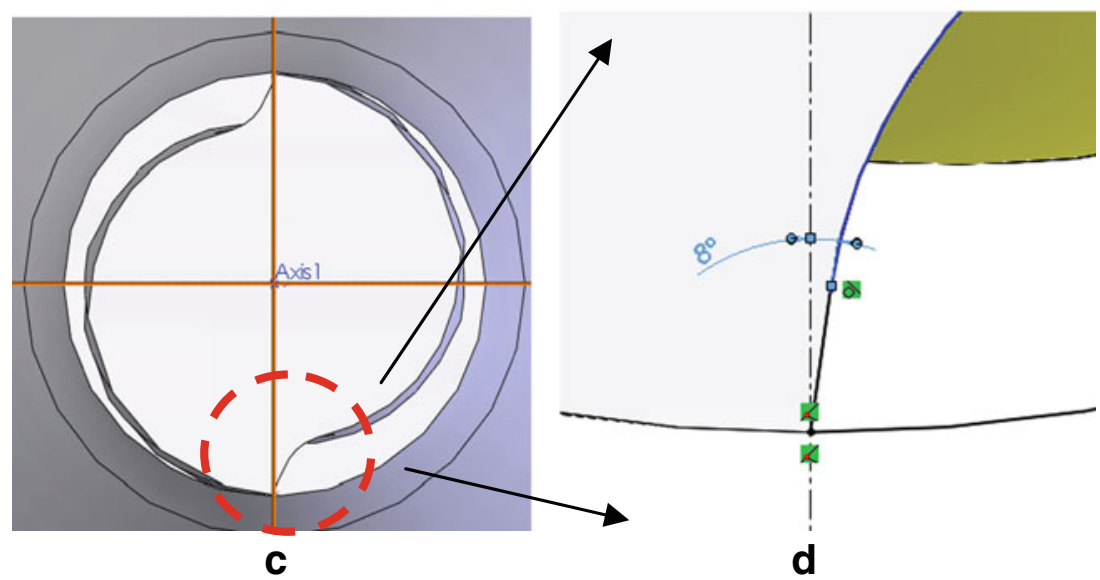

d
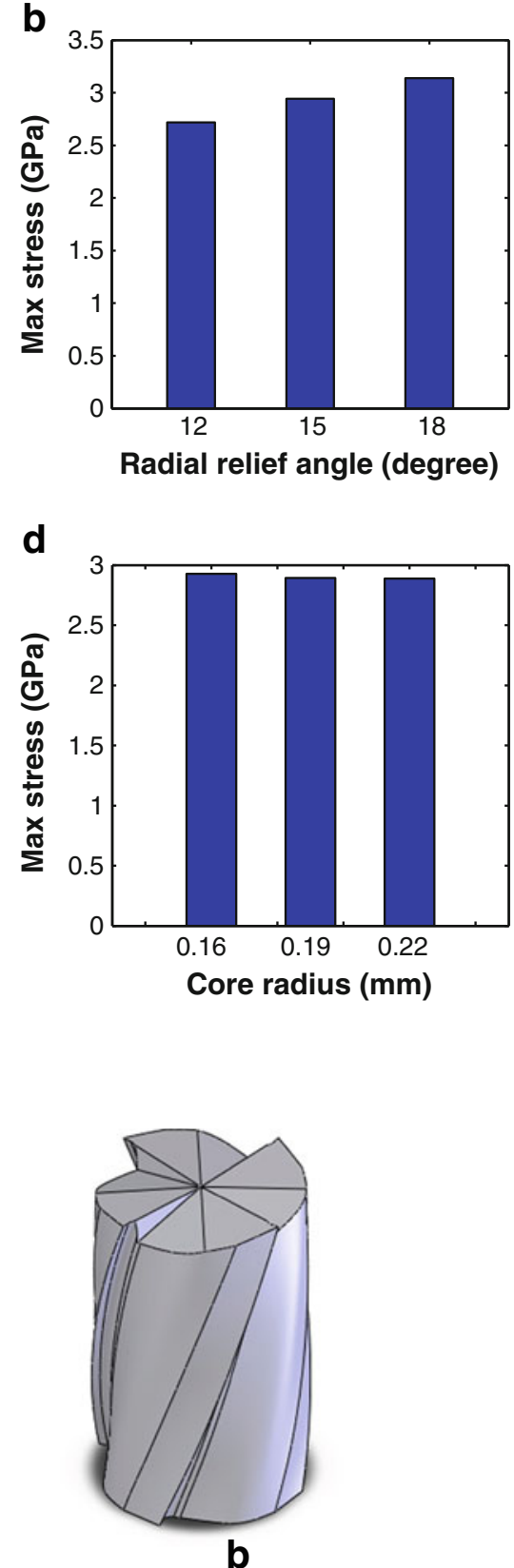

b 


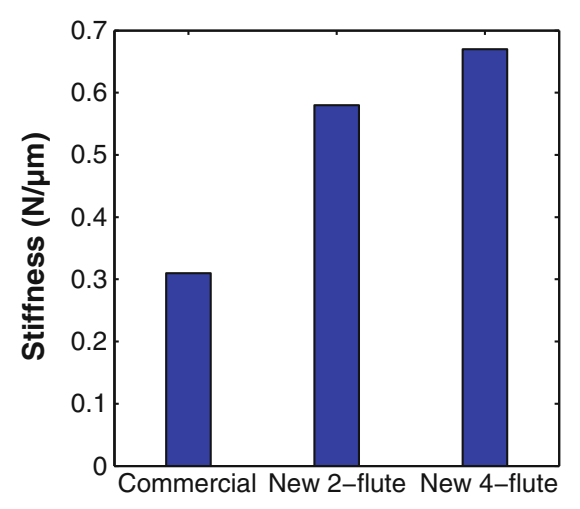

Fig. 11 Comparison of stiffness of the three types of endmills

The results, shown in Fig. 6, revealed that for the given commercial tool geometry the maximum normal stress locates at the cutting edge corners. Under the specifications of the commercial tool, the cutting edge corner is relatively 'sharp' with less backbone material, which reduces the strength of the cutting edge significantly. This analysis showed that the tool geometry is one of the direct reasons for the observed tool failure and explained why the cutting edge corners broke away at a very early stage of the machining, leading to a significant reduction of the cutting diameter.

\section{Design of micro square endmills}

\subsection{Guidelines for the redesign of micro square endmills}

Based on experimental investigations and theoretical analysis, design guidelines for micro square endmills for hard milling applications are generated.

- High stiffness: To reduce bending of the tool during machining and minimize the risk of chatter.

- Elevated strength at the cutting edge corners: To avoid chipping at early stage of machining and improve tool life.

- Simple geometry: Due to the limitation of the manufacturing process (grinding), complex features cannot be realized accurately on the micro endmills.
- Runout compensation: It will be preferable if the runout can be compensated to a certain extend by a proper design of the tool geometry.

- Others: Avoid stress concentrations, improve dynamic behaviour of the tool, etc.

\subsection{Tool stiffness}

A three-section cantilever beam model was used to qualitatively study the influence of geometrical features (neck angle and underneck length) on tool static stiffness using the Euler Bernoulli beam equations. The relative effect of each geometrical feature on tool stiffness and its trend are of interest. The beam model was chosen because it offers a convenient way to test a geometrical feature at different levels. The shank diameter and cutting diameter were fixed at 6 and $0.5 \mathrm{~mm}$, respectively because they are used by the tool supplier. Static stiffness was studied since it is decisive to the form accuracy of the machined micro features and bending of the cutting tool during machining.

Referring to Fig. 1, a micro endmill basically includes three parts, namely, the shank, neck, and cutting part. From the catalogue of the tool supplier, two values are available for the underneck length $\left(l_{\mathrm{c}}\right)$, namely, 0.8 and $3 \mathrm{~mm}$, listed in Table 1. By applying the cantilever beam theory, the deflection at the tool tip can be calculated when a static force is applied at the tool tip end. The calculated deflection and stiffness for these two types of tools are shown in Fig. 7 when a force of $10 \mathrm{~N}$ was applied.

It is seen in Fig. 7a that when $l_{c}$ is $0.8 \mathrm{~mm}$, the total deflection at the tool tip is about $13.7 \mu \mathrm{m}$ under a $10-\mathrm{N}$ force. Therefore, the stiffness of the tool is $0.73 \mathrm{~N} / \mu \mathrm{m}$. This total deflection can be decomposed into contributions from the three parts of the tool. The deflection at the end of the shank part is $3.0 \mu \mathrm{m}$, which is $21.9 \%$ of the total deflection. The corresponding values for the neck part and cutting part are $6.1 \mu \mathrm{m}(44.5 \%)$ and $4.6 \mu \mathrm{m}(33.6 \%)$, respectively. It is seen that when the cutting part is short (e.g. $0.8 \mathrm{~mm}$ ), the neck part is the main contributor to the low tool stiffness. The reason is that the length of the neck $(12.9 \mathrm{~mm})$ is much longer than that of the cutting part. This analysis shows that
Table 2 Summary of cutting parameters for the tool wear tests

\begin{tabular}{lccc}
\hline & Commercial tool & New design 2-flute & New design 4-flute \\
\hline Spindle speed $(\mathrm{rpm})$ & 30,000 & 30,000 & 30,000 \\
Cutting speed $\left(v_{\mathrm{c}}\right)(\mathrm{m} / \mathrm{min})$ & 47.1 & 47.1 & 47.1 \\
Feed per tooth $(\mu \mathrm{m})$ & 6 & 6 & 3 \\
Feed rate $\left(v_{\mathrm{f}}\right)(\mathrm{mm} / \mathrm{min})$ & 360 & 360 & 360 \\
Depth of cut $\left(a_{\mathrm{p}}\right)(\mathrm{mm})$ & 0.07 & 0.07 & 0.07 \\
Width of cut $\left(a_{\mathrm{e}}\right)(\mathrm{mm})$ & 0.5 & 0.5 & 0.5 \\
Material removal rate $\left(\mathrm{mm}^{3} / \mathrm{min}\right)$ & 12.6 & 12.6 & 12.6 \\
\hline
\end{tabular}


a

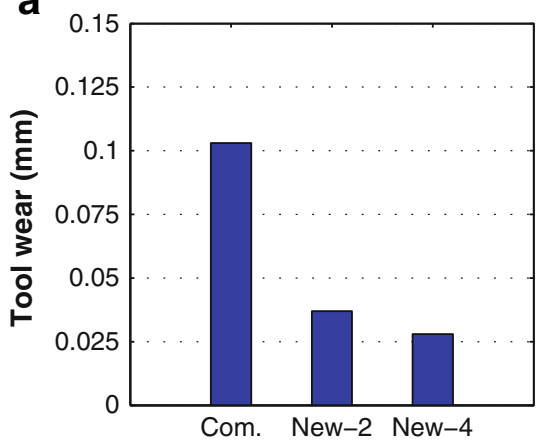

b

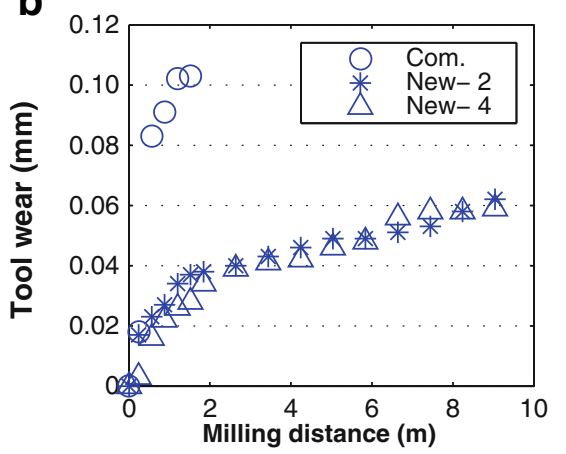

Fig. 12 Tool wear test result by using three types of endmills. a Comparison of tool wear after material removal of $5.32 \mathrm{~mm}^{3}$ and $\mathbf{b}$ total milling distance by the three types of endmills

special attention has to be paid to the neck geometry in order to improve the tool stiffness.

When the underneck length is $3 \mathrm{~mm}$, the tool stiffness is calculated to be $0.07 \mathrm{~N} / \mu \mathrm{m}$. In this case, the underneck length will contribute to $92.0 \%$ of the total tool deflection, as shown in Fig. 7b. Therefore, unless required by the application, micro endmills with short underneck lengths should be chosen in micromilling to minimize possible tool bending.

There are two possibilities to improve the tool stiffness: optimizing the neck angle or adjusting the underneck length. Additional analyses, in Fig. 8, showed that the bigger the neck angle is, the higher the tool stiffness. The shorter the tool underneck length is, the higher the tool stiffness. However, the practical values of these two geometrical features are also constrained by many other factors, such as the tool manufacturing process and the requirements of the application (e.g. the achieved aspect ratio).

\subsection{Strength of cutting edges}

The strength of the cutting edges was studied qualitatively by using the CAD and FEM model, same as presented in Section 2.4. Some key geometrical features, such as the radial rake angle, relief angle, core radius, and helix angle, were tested at three different levels to check their effect on the maximum stress on cutting edge corners. The results are shown in Fig. 9.

Among these geometrical features, the effect of the radial rake angle and helix angle is more significant on the maximum stress than that of the core radius and radial relief angle. The $+8^{\circ}$ rake angle tool has maximum stress, which means that the cutting edge corner is weakened by choosing a positive rake angle. This is the reason why the commercial tools show severe reduction of cutting diameter at the very early stage of machining. Therefore, a negative rake angle is preferable for micro square endmills in hard milling applications. Because the actual depth of cut in micromilling is relatively small, a small helix angle will not influence the chip removal significantly. Although the core radius has no significant effect on the stress level, a big core radius will increase the stiffness of the tool.

\subsection{Design of new endmills}

For the neck part of the tool, a bigger neck angle and a shorter underneck length were chosen to give the tool a higher stiffness. For the cutting part of the tool, the cross section of the endmill was improved to lower the stress concentration at the edge corner. Besides the 2-flute scenario, the four-flute is also used for the new design on purpose of compensating the process runout, as shown in
Fig. 13 Top view of the newly designed micro endmills after slot milling of $9 \mathrm{~m}$ : a newly designed two-flute endmill and b newly designed four-flute endmill
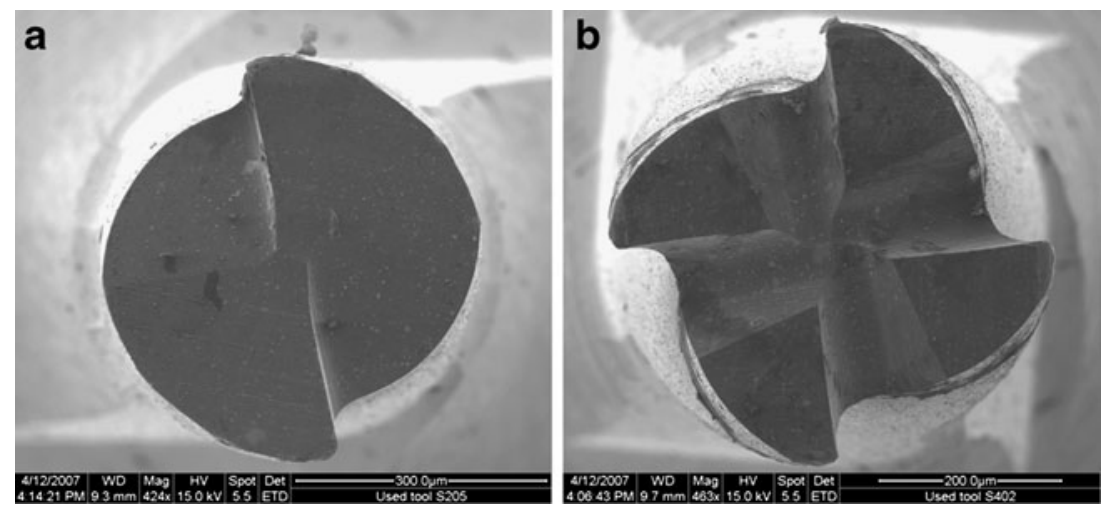
Fig. 10. The key features of the newly designed endmills are listed in Table 1 under the column of new design twoflute and new design four-flute. It is noted that the chosen values are only used to verify the trend observed from the theoretical study. They are not optimized since optimum tool geometry depends on the specific application.

\section{Experimental validation of the new design}

The newly designed $\varnothing 0.5-\mathrm{mm}$ square endmills were manufactured and verified through experiments. Firstly, the static stiffness of the micro endmills was measured. Then, the newly designed endmills were used in hard milling machining to test their wear behaviour.

\subsection{Stiffness of the micro endmills}

Three types of micro endmills were rigidly clamped to a mechanical clamping device at the shank part. Known static loads were applied at the tool tip end gradually, and the displacement of the tool tip was read out by a Keyence VHX-100 microscope.

The measured stiffness is shown in Fig. 11. It shows that the newly designed endmills are about two times stiffer than the commercial tool. The experimental measured stiffness for the commercial endmill was $0.3 \mathrm{~N} / \mu \mathrm{m}$. The measured stiffness of the newly designed two-flute and four-flute endmill was 0.6 and $0.7 \mathrm{~N} / \mu \mathrm{m}$, respectively. The stiffness of the four-flute endmill is a bit higher than that of the newly designed two-flute endmill. This is because more material was removed from the tool neck part on the two-flute endmill during the tool manufacturing process.

It is also seen that the improvement of tool stiffness by only tool geometry is limited due to the small cutting diameter of the micro endmills. To further improve tool stiffness, measures have to be taken from other aspects, such as tool substrate material.

\subsection{Tool wear tests}

As described in Section 1, there are many factors influencing tool performance besides tool geometry. To minimize the effect of those factors, the strategy used in experiments was to compare three types of tools under the same cutting conditions, such as machine tool, cutting conditions, and lubrication. To get confidence in the results, experiments were repeated on different machine tools under different combinations of cutting conditions.

The first comparison test was done to machine AISI H11 with 56 HRC. The cutting conditions are listed in Table 2. The material removal rate was kept the same for a fair
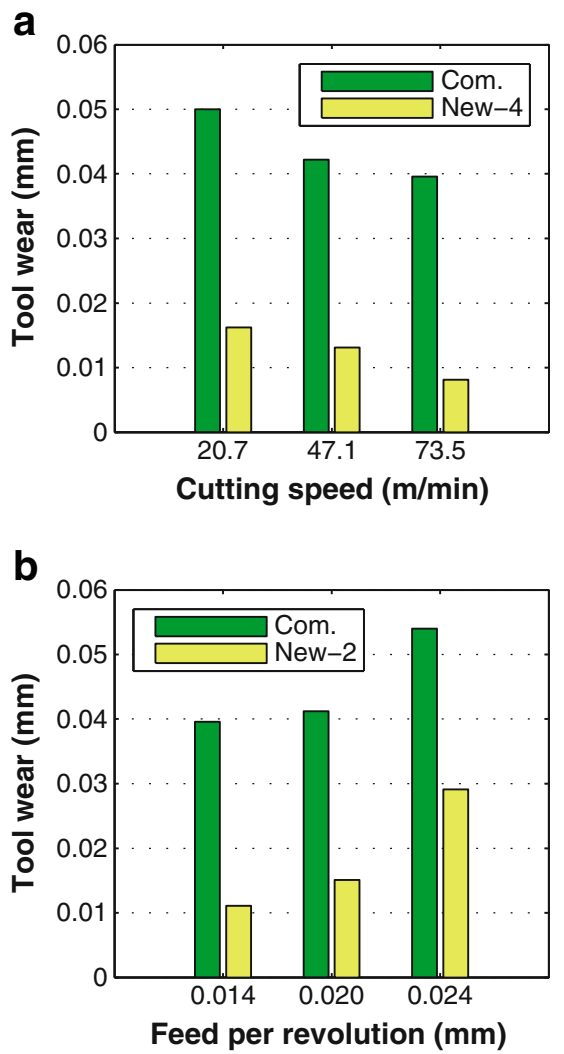

Fig. 14 Comparison of tool wear. The material removal for each tool was kept the same at $20 \mathrm{~mm}^{3}$, workpiece material AISI H11 with 54 HRC, spindle speed 30,000 rpm, slot milling. a Various cutting speed and $\mathbf{b}$ various feed per revolution

comparison. Tool wear, workpiece form accuracy, and burr formation were measured or observed after a certain interval.

The tool wear test results are shown in Fig. 12. After material removal of $5.32 \mathrm{~mm}^{3}$, the wear of the commercial micro endmill was about $103 \mu \mathrm{m}(20.7 \%$ of the tool nominal cutting diameter), while the wear of the newly designed two-flute and four-flute endmills was about 38 and $28 \mu \mathrm{m}$, respectively. The total milling distance of the

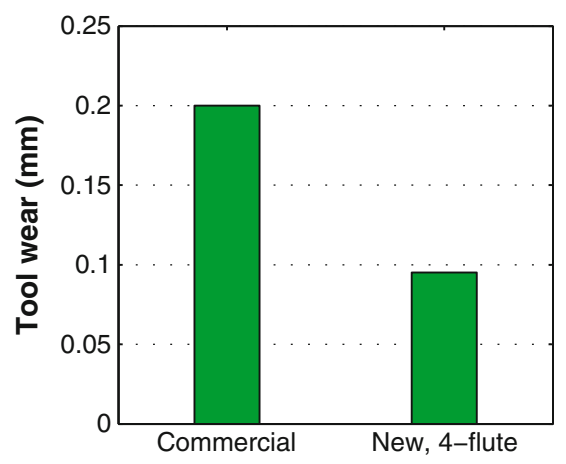

Fig. 15 Tool wear in machining of AISI D2 with 50 HRC. Material removal was kept the same at $20 \mathrm{~mm}^{3}$ for each tool. Slot milling, spindle speed $30,000 \mathrm{rpm}, a_{\mathrm{p}} 0.07 \mathrm{~mm}, f_{\mathrm{z}} 7 \mu \mathrm{m}$ 
Fig. 16 Comparison of burr formation by the a commercial endmill and $\mathbf{b}$ newly designed two-flute endmill after material removal of $5.32 \mathrm{~mm}^{3}$
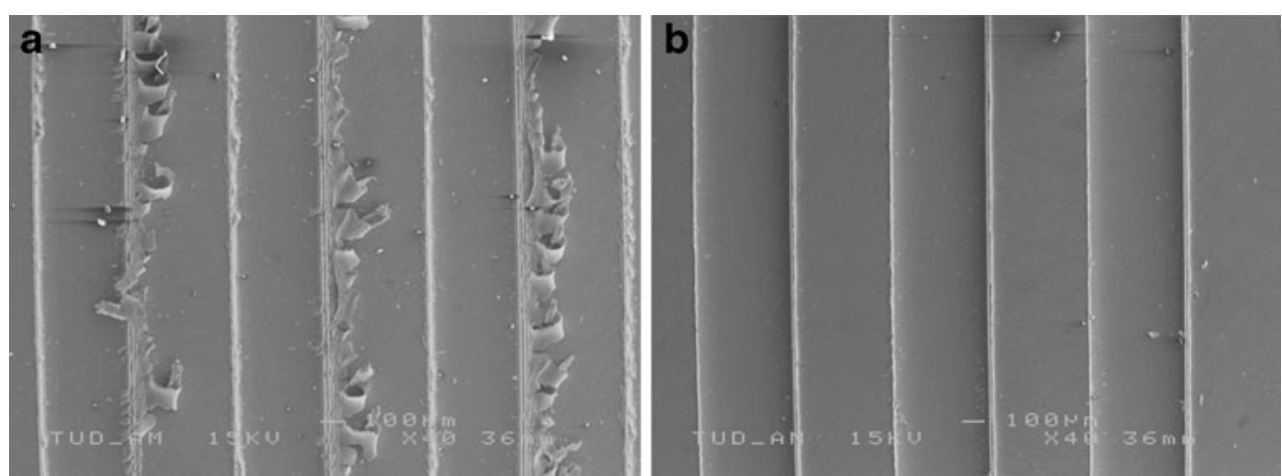

newly designed tools was about six times longer than that of the commercial tool. After slot milling of $9 \mathrm{~m}$, the newly designed endmills still kept good shape of cutting edge corners, as shown in Fig. 13, in comparison to the commercial tool, as shown in Fig. 3.

The results of the second comparison test are shown in Fig. 14, which illustrates that the wear of the newly designed endmills was much less than that of the commercial tools when machining AISI H11 with 54 HRC under different combinations of machining parameters. The third comparison test was to machine AISI D2 with $50 \mathrm{HRC}$, which is a known difficult-to-machine material in macro scale hard milling. As shown in Fig. 15, the wear magnitude of each type of micro tools is indeed much higher than that in machining AISI H11 with 54 HRC. However, the newly designed endmills still showed significant less wear than the commercial tool. This test also showed that the improvement of tool life is limited by only redesigning the tool geometry. To further improve tool performance, other measures have to also be taken into account.

Besides, it was observed in experiments that the wear on the two pairs of cutting edges of the four-flute endmill was about the same in magnitude. It means that the wear was more evenly distributed in the two directions of the four cutting edges.

\subsection{Workpiece quality}

Since the wear on the newly designed endmills has been reduced, the workpiece quality was also improved accordingly, in terms of form accuracy and burr formation. Figure 16 shows the top view of the milled slots using a commercial tool and a newly designed two-flute tool after milling the same distance. It is clearly seen that the burr size on both edges of the slots milled by the commercial tool was much bigger than that by the newly designed tool. Burr formation is closely related with the tool condition. When the cutting edge corners of the micro endmills broke, the material removal process became more ploughing, instead of shearing. The workpiece material attached to the edge of the slot forming burrs. Because the newly designed endmill retained a good shape of cutting edges, burr formation was reduced. The same reason is applied for the improvement of form accuracy, as shown in Fig. 17.

The surface roughness of the machined workpiece was measured by Talyor Hobson. The surfaces machined by the three types of endmills were comparable in magnitude, better than $0.3 \mu \mathrm{m}(R a)$. This value is acceptable for industrial applications.

\subsection{Milling force}

The milling forces generated by the three types of micro endmills were measured by Kistler MiniDyn 9256C2. The threshold of the sensor is $2 \mathrm{mN}$ which makes it suitable to measure low magnitude forces accurately in micromilling. The average force in the cross feed direction at different stage of machining is shown in Fig. 18. It is seen that the initial force of the newly designed four-flute endmill was
Fig. 17 Side view of the milled slots after material removal of $5.32 \mathrm{~mm}^{3}$ : a by the commercial tool and $\mathbf{b}$ by the newly designed two-flute endmill
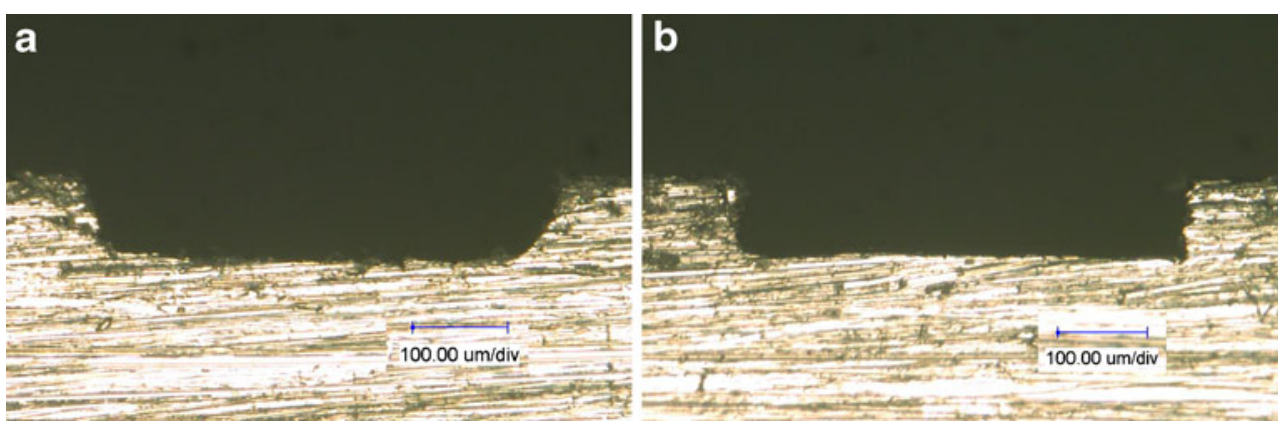


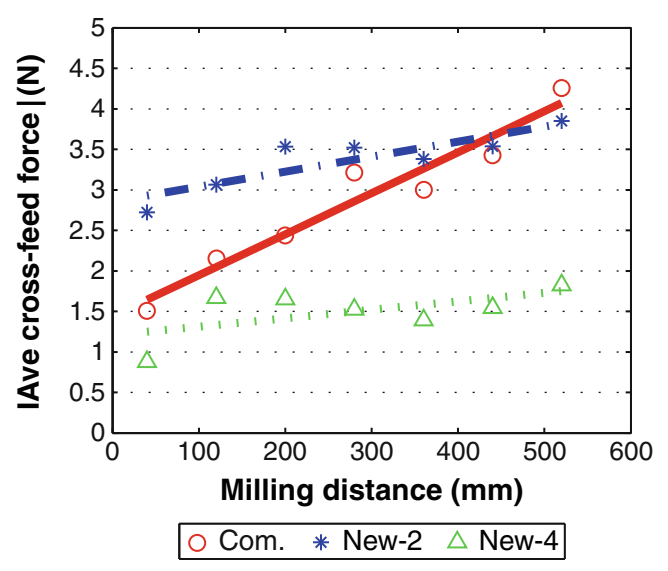

Fig. 18 Comparison of the average cross feed force by the three types of micro endmills

the lowest and the initial force on the newly designed twoflute tool was the highest. This is expected because the feed per tooth used on this four-flute tool was half of the other two types of tools, and the newly designed tools have a negative rake angle.

With the increase of milling distance, the average force for the three types of endmills also increased, which indicates the increase of tool wear. The slope for the force of the commercial endmill was the biggest among all three types of tools, which means that the condition of the commercial tool changed rapidly. In comparison, the slopes for the force curves of the two newly designed endmills are much smaller, which means the tool conditions were relatively stable during cutting.

\section{Conclusions}

During experiments with commercial $\varnothing 0.5 \mathrm{~mm}$ square endmills in machining of hardened tool steel, it was observed that the micro endmills suffered from severe tool wear even at early stage of machining. Due to the scaling down of cutting geometry, micro endmills showed different dominant wear types. In micromilling, small values of depth of cut and feed per tooth are used; as a result, the cutting is mainly done by the cutting edge corners. Once the cutting edge corners wear out, the geometry of the endmills changes largely. This shortened tool life and led to unsatisfactory workpiece quality in terms of form accuracy and burr formation.

The geometry of commercial micro endmills was studied. It was observed that the geometry was mainly derived from that of macro endmills. By using such a geometry, the maximum stress locates at the cutting edge corners, which will break first under excessive milling forces.

It was proposed in this research that the geometry of micro endmills should be designed by taking into the scaling effect and adaptively for the application. This is because micro endmills show different dominant wear types in machining low strength materials and high strength materials. In this work, the geometry of $\varnothing 0.5 \mathrm{~mm}$ micro square endmills was redesigned for hard milling application. The effect of some key features, such as rake angle and relief angle, was studied by FEM in terms of tool stiffness and stress distribution. Based on the theoretical study, micro endmills were redesigned and verified in experiments. The experimental results showed the performance of micro endmills can be improved by a proper design.

It was also observed that tool performance can be improved to a certain extent by redesigning tool geometry. To further improve the reliability of the micromilling process, factors, such as machine tool, tool substrate material, workpiece material, and cutting conditions, should be designed carefully.

Acknowledgements This work is being supported by the Innovation Research Program (IOP) of the Dutch Government. The authors wish to gratefully acknowledge Van Hoorn Hardmetaal Production B.V., Netherlands for the help of manufacturing the newly designed endmills. Some experiments were conducted at Mondragon University in Spain. The authors gratefully acknowledge their cooperation in this research.

Open Access This article is distributed under the terms of the Creative Commons Attribution Noncommercial License which permits any noncommercial use, distribution, and reproduction in any medium, provided the original author(s) and source are credited.

\section{References}

1. Bissacco G, Hansen HN, De Chiffre L (2006) Size effects on surface generation in micro milling of hardened tool steel. Ann CIRP 55(1):1-4

2. Schmidt J, Tritschler H (2004) Micro cutting of steel. Microsyst Technol 10:167-174

3. Aramcharoen A, Mativenga PT (2008) Tool wear modes in micro/ mesoscale milling of hardened die steel. Proc. 3rd International CIRP High Performance Cutting Conference 1:179-188.

4. Bao WY, Tansel IN (2000) Modeling micro-end-milling operations. Part III: influence of tool wear. Int J Mach Tools Manuf 40:2193-2211

5. Tansel IN, Rodriguez O, Trujillo M, Paz E, Li W (1998) Microend-milling-I. Wear and breakage. Int J Mach Tools Manuf 38:1419-1436

6. Miyaguchi T, Masuda M, Takeoka E, Iwabe H (2001) Effect of tool stiffness upon tool wear in high spindle speed milling using small ball end mill. Precis Eng 25:145-154

7. Filiz S, Conley CM, Wasserman MB, Ozdoganlar OB (2007) An experimental investigation of micro-machinability of copper 101 using tungsten carbide micro-endmills. Int J Mach Tools Manuf 47:1088-1100

8. Rahman M, Kumar AS, Prakash JRS (2001) Micro milling of pure copper. J Mater Process Technol 116:39-43

9. Uriarte L, Herrero A, Zatarain M, Santiso G, Lopéz de Lachalle LN, Lamikiz A, Albizuri J (2007) Error budget and stiffness chain assessment in a micromilling machine equipped with tools less than $0.3 \mathrm{~mm}$ in diameter. Precis Eng 31:1-12

10. Takács M, Verö B, Mészáros I (2003) Micromilling of metallic materials. J Mater Process Technol 138:152-155 
11. Lee K, Dornfeld DA (2005) Micro-burr formation and minimization through process control. Precis Eng 29:246-252

12. Schaller T, Bohn L, Mayer J, Schubert K (1999) Microstructure grooves with a width of less than $50 \mathrm{~mm}$ cut with ground hard metal micro end mills. Precis Eng 23:229-235

13. Dimov SS, Pham DT, Ivanov A, Popov K (2005) Micromilling of thin features. Proc First International Conference on MultiMaterial Micro Manufacture. 363-366

14. Dow TA, Miller EL, Garrard K (2004) Tool force and deflection compensation for small milling tools. Precis Eng 28:31-45

15. Salgado MA, López de Lacalle LN, Lamikiz A, Muñoa J, Sánchez JA (2005) Evaluation of the stiffness chain on the deflection of end-mills under cutting forces. Int $\mathrm{J}$ Mach Tools Manuf 45:727-739
16. Schmidt J, Tritschler H, Haberer H (2001) Cutting tools and material conditioning for micro end milling of tool steel. Proc. 2nd Euspen International Conference 624-627.

17. Uhlmann E, Schauer K (2005) Dynamic load and strain analysis for the optimization of micro end mills. Ann CIRP 54(1):75-78

18. Fang FZ, Wu H, Liu XD, Liu YC, Ng ST (2003) Tool geometry study in micromachining. J Micromech Microeng 13:726-731

19. Adams DP, Vasile MJ, Benavides G, Campbell AN (2001) Micromilling of metal alloys with focused ion beam-fabricated tools. Precis Eng 25:107-113

20. Liu X, DeVor RE, Kapoor SG, Ehmann KF (2004) The mechanics of machining at the microscale: assessment of the current state of the science. J Manuf Sci Eng 126:666-678

21. Tlusty G (2000) Manufacturing processes and equipment. Prentice-Hall, New York 